\title{
Cues That Hippocampal Place Cells Encode: Dynamic and Hierarchical Representation of Local and Distal Stimuli
}

\author{
Matthew L. Shapiro, ${ }^{1 *}$ Heikki Tanila, ${ }^{2}$ \\ and Howard Eichenbaum ${ }^{3}$ \\ ${ }^{1}$ Department of Psychology, McGill University, \\ Montreal, Canada \\ ${ }^{2}$ Department of Neuroscience and Neurology, \\ University of Kuopio, Kuopio, Finland \\ ${ }^{3}$ Department of Psychology, Boston University, \\ Boston, Massachusetts
}

\begin{abstract}
Hippocampal place fields were recorded as rats explored a four-arm radial maze surrounded by curtains holding distal stimuli and with distinct local tactile, olfactory, and visual cues covering each arm. Systematic manipulations of the individual cues and their interrelationships showed that different hippocampal neurons encoded individual local and distal cues, relationships among cues within a stimulus set, and the relationship between the local and distal cues. Double rotation trials, which maintained stimulus relationships within distal and local cue sets, but altered the relationship between them, often changed the responses of the sampled neural population and produced new representations. After repeated double rotation trials, the incidence of new representations increased, and the likelihood of a simple rotation with one of the cue sets diminished. Cue scrambling trials, which altered the topological relationship within the local or distal stimulus set, showed that the cells that followed one set of controlled stimuli responded as often to a single cue as to the constellation. These cells followed the single cue when the stimulus constellation was scrambled, but often continued firing in the same place when the stimulus was removed or switched to respond to other cues. When the maze was surrounded by a new stimulus configuration, all of the cells either developed new place fields or stopped firing, showing that the controlled stimuli had persistent and profound influence over hippocampal neurons. Together, the results show that hippocampal neurons encode a hierarchical representation of environmental information. Hippocampus 1997;7:624-642. ๑ 1997 Wiley-Liss, Inc.
\end{abstract}

KEY WORDS: hippocampus; place cells; spatial learning; memory; stimulus encoding

\section{INTRODUCTION}

The hippocampus is one of several medial temporal lobe structures associated with memory function (Scoville et al., 1957). Bilateral damage to the medial temporal lobes produces a severe amnesia in humans, nonhu-

*Correspondence to: Matthew Shapiro, Department of Psychology, McGill University, 1205 Dr. Penfield Ave., Montreal, QC H3A 1B1, Canada. E-mail: matthew@psych.mcgill.ca

Accepted for publication 10 ctober 1997 man primates, rodents, and other species (Krebs et al., 1989; Cohen and Eichenbaum, 1993). Rapid spatial learning and recent memory for places is especially impaired by hippocampal lesions, which prevent rats from learning rapidly about places in the radial and water mazes (Morris et al., 1982; Jarrard, 1993) and impair spatial working memory in these tasks (O'Keefe et al., 1978; Olton et al., 1979).

In parallel with the findings on hippocampal damage and spatial learning, hippocampal neuronal activity reflects the processing of spatial information. As a rat moves through its environment, individual hippocampal pyramidal cells fire when the rat is in a specific location (O'Keefe and Dostrovsky, 1971; O'Keefe, 1976). In the context of spatial behavior, these cells are called place cells, and the regions where the cells fire maximally are called place fields. The spatial correlates of hippocampal neuronal activity provides a robust example of hippocampal information processing and is advantageous for analyzing the stimulus coding properties of these neurons (Eichenbaum and Wiener, 1989; Wiener et al., 1989; Muller, 1996).

Many experiments have examined the spatial properties of hippocampal place cells. The early experiments aimed to identify the critical spatial cues and were carried out in highly complex environments in which the relevant spatial cues are difficult to identify and control, such as a radial maze in a large room filled with many potential cues (O'Keefe and Nadel, 1978; Olton et al., 1978). To gain experimental control of the stimuli and ongoing behavior, several investigators have used highly simplified environments, such as a cylinder with a single stripe (Muller and Kubie, 1987; Muller et al., 1987), a box with plain walls (Wiener et al., 1989), or a straight runway (O'Keefe and Burgess, 1996). In these 
situations distal visual stimuli were emphasized whereas local cues were minimized by randomizing their locations, by making them irrelevant to task performance (O'Keefe and Speakman, 1987; O'Keefe and Burgess, 1996), and sometimes by randomizing the location of ongoing behavior relevant to those cues (Muller and Kubie, 1987; Muller et al., 1987). Typically in these studies, when the emphasized distal visual stimuli were rotated around the maze center, place cells continued to fire in the same topological relation to the stimuli, rotating in correspondence with the emphasized stimuli (O'Keefe and Conway, 1978; Muller and Kubie, 1987; O'Keefe and Speakman, 1987).

By manipulating controlled cues in these simplified environments, much has been learned about which cues and spatial relations are employed in hippocampal representations. For example, in situations where there were multiple controlled cues, when any one of them was removed, the place cells often seemed unaffected, continuing to fire in the same location as before the stimulus was removed (O'Keefe and Conway, 1978). However, if the topological relationship among the stimuli was altered by interchanging the stimuli, or if many extramaze stimuli were removed, then the place fields usually degraded (O'Keefe and Nadel, 1978; O'Keefe, 1979; O'Keefe and Speakman, 1987; Muller and Kubie, 1987; Hetherington and Shapiro, 1997). Paradoxically, if rats are trained to perform a working memory task that requires remembering the distal stimulus configuration, place cells continue to fire normally even after all of the stimuli are removed (O'Keefe and Speakman, 1987). These and other experiments suggest that place fields respond to the perceived and remembered spatial relationships among stimuli, when important cues are eliminated (O'Keefe and Speakman, 1987; O'Keefe and Nadel, 1978; O'Keefe, 1979; Muller and Kubie, 1987). Studies that have manipulated the spatial relations among the cues have revealed that one of the most important stimulus relationships encoded by hippocampal place cells is the distance between a rat and prominent distal stimuli (O'Keefe and Burgess, 1996; Hetherington and Shapiro, 1997).

Hippocampal cellular activity also reflects nonspatial contingent variables in learning tasks, including sensory stimuli in the olfactory (Wiener et al., 1989), visual (Wible et al., 1986), and auditory (Sakurai, 1990) modalities, as well as learned behavioral responses (Berger et al., 1976; Eichenbaum et al., 1994). Correspondingly the hippocampal system is required for rats to perform working memory tasks in the radial maze both when distal spatial stimuli are emphasized and local discriminative stimuli are reduced (Olton et al., 1979), and when local discriminative stimuli are emphasized and distal stimuli are reduced (Olton and Feustle, 1981). In parallel experiments, hippocampal units responded to the behaviorally relevant and emphasized stimulus dimensions in each version of the task (Olton et al., 1978; Young et al., 1994a,b). When distal visual stimuli were available, and local stimuli were minimized, hippocampal unit activity correlated with the distal stimuli (Olton et al., 1978). Similarly, when local stimuli were available and distal stimuli were minimized, hippocampal unit activity correlated with the local stimuli as well as with spatial locations, and the best predictor of unit activity was the combination of both place and nonspatial cues (Young et al., 1994a,b). Furthermore, the same individual hippocampal cell has multiple sensory or behavioral correlates that can be reliably elicited by different experimental contingencies (Kubie and Ranck, 1983; Wiener et al., 1989). These observations suggest that each experimental situation activates a distinct but functionally effective subset of the inputs to a hippocampal cell. The relationship among these subsets, if any exists, is not understood.

The aim of the present experiment was to examine how different types of stimuli, singly and collectively, influenced hippocampal neuronal activity. Rats were implanted with chronic recording microelectrodes and trained to explore a radial maze in a cue-controlled environment with controlled prominent local and distal cues. Curtains surrounding the maze held distinct visual stimuli, and the floor of each maze arm was covered with a distinct set of tactual, visual, and olfactory stimuli (local cues). After rats had become familiar with this environment and baseline recordings provided an initial characterization of hippocampal place cells, the stimuli were manipulated to determine how the different cues affected place field representations. By altering local and distal cue sets independently, we analyzed how stimulus relationships, both within and between stimulus sets, were encoded by the hippocampus. These manipulations also allowed us to explore the hierarchy of stimulus coding within the overall structure of the hippocampal representation of the environment. We then recorded the same cells as the animal explored a different stimulus environment to compare the effects of altering stimulus relationships with those of encoding new stimulus content. Differences between young and aged rats' place fields have been described in detail elsewhere (Tanila et al., 1997a-c).

Consistent with traditional descriptions, the constellation of distal stimuli often had an important influence on place fields. Contrary to these descriptions, both individual distal cues and groups of local cues influenced place field firing significantly, and the extent of these responses changed with experience. Furthermore, the relationship between the local and distal cue sets, as well as the remembered location of transient cues were also encoded by hippocampal neurons. Together, the results suggest that to implement cells that respond when a rat is in a place, the hippocampus encodes information about specific stimulus contents within complex environments in addition to the spatial relationships among these stimuli. The flexible and systematic responses of individual hippocampal neurons to different subsets of environmental cues suggest that the cells encode stimuli hierarchically.

\section{MATERIALS AND METHODS}

\section{Subjects}

Ten adult (male Long-Evans rats, 450-700 g, 4-6 months old) were housed individually (12-hour light cycle) with free access to food and water throughout the experiment. 


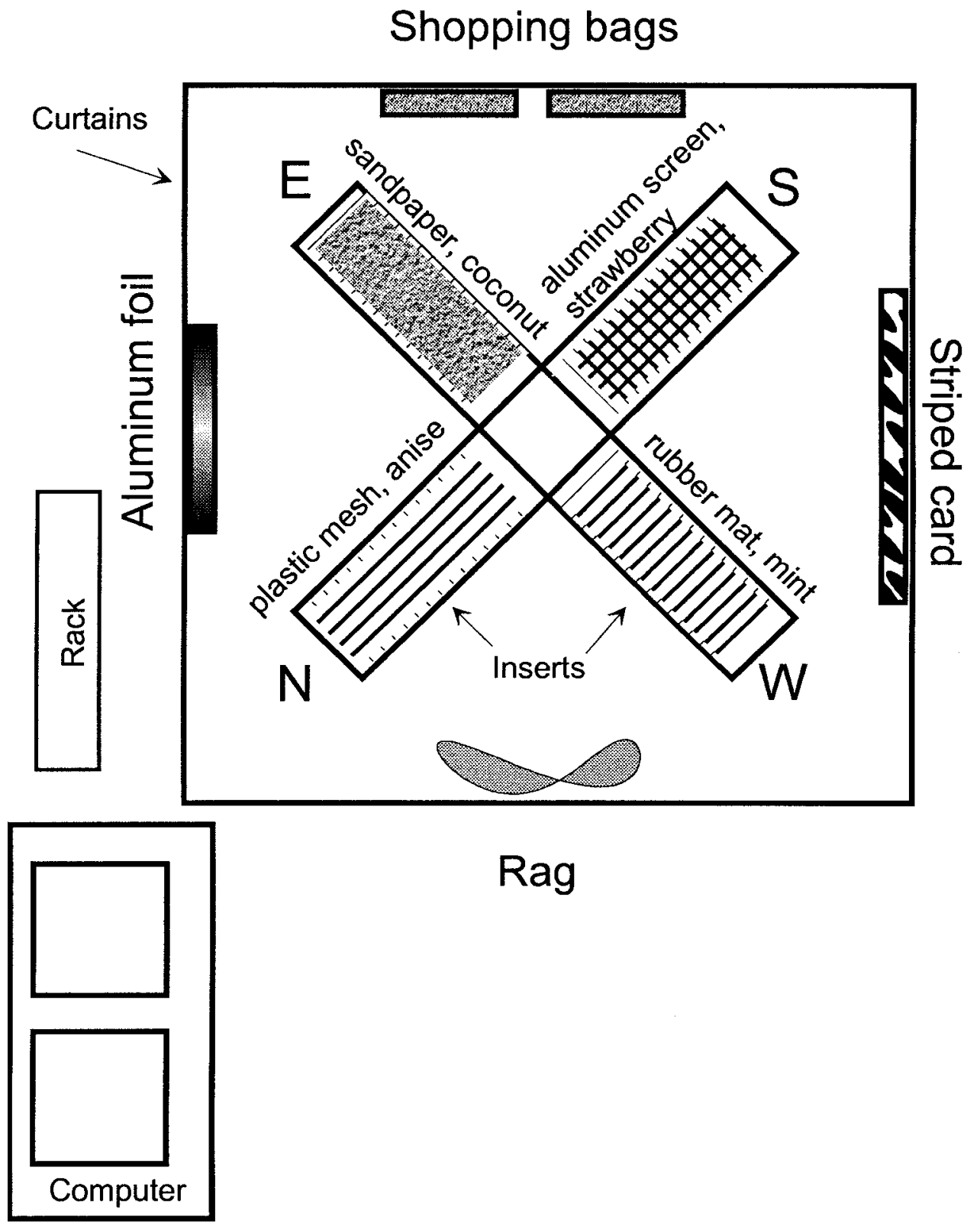

FIGURE 1. The recording chamber contained a four-arm maze that was surrounded by curtains that held distal stimuli. Each arm of the maze was covered by an insert that contained distinct visual, olfactory, and tactile cues. The recording equipment was outside the curtained enclosure.

\section{Recording Room and Maze}

Units were recorded while rats explored a four-arm radial maze (Fig. 1). The maze was elevated $70 \mathrm{~cm}$ above the floor, with an octagonal central platform (12 cm on each side) and arms $45 \mathrm{~cm}$ long, $10 \mathrm{~cm}$ wide, with edges $2 \mathrm{~cm}$ high except that the end of each arm had 6-cm, steeply angled edges.

The recording room contained both distal and local controlled cues that were organized in the following configuration, hereafter called the Standard condition. The maze was surrounded by four black curtains (175 cm wide). A 30- to 90-cm-wide distal cue was suspended from each curtain (two shopping bags [SE], a striped card [SW], a white rag with cut holes held in an arc [NW], and an aluminum foil-covered card [NE]). An insert covered the floor of each maze arm that provided a different tactile surface, and each insert was sprayed with a distinct olfactory stimulus providing multimodal local cues (coarse plastic mesh/anise, N; sandpaper/ coconut, E; fine wire mesh/strawberry, $\mathrm{S}$; and coarsely ridged rubber/peppermint, $\mathrm{W})$. The distal stimuli and the maze inserts were used to test their individual and collective influence on place fields.

The maze was illuminated by four $12-\mathrm{V}$ DC lights located symmetrically on a ceiling panel above the maze. White noise was 
delivered by two speakers on the ceiling panel. The curtained enclosure could be entered from two opposite corners. The recording equipment was outside the curtain.

\section{Electrodes and Microdrives}

Tetrodes (Recce and O'Keefe, 1989) were constructed from four 25- to 30- $\mu \mathrm{m}$, formvar-insulated, nichrome wires $(.0012$ inch, 250-700 k $\omega$, impedance at 1,000 Hz, California Fine Wire Co., Grover City, CA) twisted and held together with superglue. Two single wires identical with those used for the tetrodes served as indifferent leads for differential amplification. One tetrode and the two indifferent electrodes were held in a microdrive assembly, fixed with epoxy in a 29-gauge stainless steel guide tube (Small Parts Inc., Miami Lakes, FL). The tetrode wires were cut $1.5 \mathrm{~mm}$ from the end of the guide tube, and the ends of the two shorter indifferent wires were retracted $.25 \mathrm{~mm}$ and $.5 \mathrm{~mm}$ above the tetrode. The guide tube was held by a second 24-gauge, thin-wall tube which was advanced by the rotation of an \#0-80 set screw (314 $\mu \mathrm{m}$ per full rotation) mounted in an amphenol connector and withdrawn by the pressure of two stainless steel miniature springs (.016 inch, \#6 gauge). Rotation of the set screw allowed approximately $2.5 \mathrm{~mm}$ of dorso-ventral movement.

Lateral hypothalamus stimulating electrodes and ground-screw connectors were constructed from a twisted pair of 100- $\mu \mathrm{m}$, isonel-insulated, stainless steel wires (MWS Wire Industries, West Lake Village, CA).

\section{Surgery}

Prior to surgery, the 24-gauge tube of the microdrive was coated with sterile petroleum jelly, and the electrodes were soaked in alcohol and Betadine (7.5\% povidone-iodine, Purdue Frederick, Toronto, ON) for $10 \mathrm{~min}$. Rats were pretreated with $100 \mu \mathrm{l}$ atropine methyl bromide (2 mg/kg i.p., Sigma Chemical Co., St. Louis, MO), tranquilized with ketamine and xylazine $(10 \mathrm{mg}$ each, i.m.), and anesthetized with pentobarbital (50 mg/kg, i.p.). After surgical level of anesthesia was ensured, the rat was placed in a stereotaxic apparatus, with bregma and lambda in the horizontal plane. The rat's eyes were coated with ophthalmological ointment to prevent corneal damage, and body temperature was held constant with a heating pad. The scalp was incised and retracted, and six 1-mm burr holes were drilled for placement of the tetrodes, lateral hypothalamus electrodes, and four bone screws. Lateral hypothalamus electrodes were aimed at the medial forebrain bundle of the left hemisphere ( $\mathrm{mm}$ from bregma: AP, 0.5 ; $\mathrm{L}$, 1.5; V, $8.3 \mathrm{~mm}$ from skull surface, Paxinos \& Watson Stereotaxic Atlas). Tetrodes were positioned over the CA1 and CA3 pyramidal cell layers of the right hippocampus ( $\mathrm{mm}$ from bregma: AP, $3.2-3.5 ; \mathrm{L}, 2.0 ; \mathrm{V}, 1.7 \mathrm{~mm}$ from the cortical surface). The lateral hypothalamus electrodes, microdrive assembly, and electrical connector were cemented in place using grip cement and dental acrylic (Turotech, Wynnwood, PA). The microdrive extended less than $2 \mathrm{~cm}$ from the skull surface and was encircled by a dental cement crown. Each rat was given $100 \mu l$ penicillin (i.m.) after the surgery and was placed in a warm cage until it recovered from anesthesia.

\section{Unit Recording and Isolation}

Tetrode and indifferent signals were passed through a unity gain amplifier located on the headstage of the recording cable, and then through an A\&M Systems differential amplifier (5-10K gain, $0.3-3 \mathrm{kHz}$ bandpass). Amplified unit signals were played through a loudspeaker, displayed on a storage oscilloscope and computer screen, and digitized by an A/D board (12 bits, $25 \mathrm{kHz}$ each). Spikes with amplitudes three times greater than noise on any of the tetrode channels were stored on disk (Enhanced Discovery DataWave Technologies, Inc., Thorton, CO). Most units were recorded with tetrodes, but occasionally cells were recorded from the single-ended indifferent wires. In all cases, units were recorded differentially between the assigned electrode wire(s) and a nearby indifferent wire. Preliminary unit isolation was done on-line using the Spike Sort module of the Discover software. Final unit isolation was done off-line using Autocut software (DataWave Technologies, Inc.). All units were isolated by identifying clusters defined by waveform parameters (McNaughton et al., 1983). Unit stability across recording trials was assessed by comparing cluster boundaries.

\section{Position Tracking}

The rat's head location and horizontal orientation were monitored using two light bulbs attached to the end of the recording cable immediately above the rat's head. The two light bulbs of different luminance were held $6 \mathrm{~cm}$ apart, aligned with the rat's ears to help ensure that neither bulb was blocked by the recording cable, and were tracked independently. The two bulbs were contrast isolated and converted into two camera coordinates at 20 $\mathrm{Hz}$, digitized, and recorded to disk with the unit recordings. Behavioral measures of speed, distance, heading angle, and the number of lateral hypothalamus trains received were also calculated on-line and saved to disk.

\section{Computer Controlled Lateral Hypothalamus Stimulation}

Brief, 200- to 250-ms 100-Hz trains of negative-going, 500- $\mu \mathrm{s}$ monophasic, square-wave pulses were delivered across the lateral hypothalamus bipolar stimulating electrode using a Grass S8 stimulator (Grass Medical Instruments, Quincy, MA) driving a constant-current stimulus isolator (Model BSI-2, BAK Electronics, Germantown, MD) at currents ranging from 30 to $350 \mu \mathrm{A}$. Lateral hypothalamus stimulation was delivered by computer using contingencies that encouraged exploration of the radial maze (Hetherington and Shapiro, 1997). Selected points in the 
maze defined the centers of reward circles within which the rat received lateral hypothalamus stimulation. The reward circles were at the end of each arm of the radial maze. To obtain a reward, the rat was first required to enter the middle of the central platform of the maze and then go to the end of an arm. To encourage the rats to enter all of the arms before re-entering one, repeated entry to an arm before all of the arms were visited was not rewarded. The reward circles were defined by the computer and were only apparent to the rat as lateral hypothalamus stimulation contingencies.

The reward circle size was held constant for each trial but could vary during the training of the rat. Larger reward circles (20-30 $\mathrm{cm}$ diameter) were used to train the animal and were reduced in size as the animals entered the arms of the maze readily. The smallest reward circles used were $5 \mathrm{~cm}$, while most ranged from 10 to $24 \mathrm{~cm}$. Performance often improved by slightly increasing the lateral hypothalamus stimulation current or the reward circle diameter.

\section{Recording Protocol}

Behavioral training and unit recording began 3-7 days after surgery, at least 1 day after the rat's weight returned to normal. At the start of training, lateral hypothalamus stimulation current was $100 \mu \mathrm{A}$, and the reward circle diameter was $30 \mathrm{~cm}$. These parameters were adjusted to encourage the animals to walk to the end of each arm and return to the center of the maze reliably and repeatedly. To obtain a reward, the rat had to enter each arm once before re-entering an arm. Thus, the behavior was controlled using working memory contingencies, defined operationally (Olton et al., 1979). The minimum stimulation current that produced reliable behavior in an individual rat was used during subsequent trials.

\section{Experimental Trials}

Unit channels were monitored throughout the training and subsequent trials. If no unit activity was observed during a 5- to 10-min trial, the electrodes were advanced 20-30 $\mu \mathrm{m}$ and the rat was returned to its home cage for at least $4 \mathrm{~h}$ to allow the brain tissue to settle around the electrode. If isolable, physiologically defined complex-spike cells were observed (Ranck, 1973; O'Keefe, 1979; Fox \& Ranck, 1981), then the cells were discriminated on line and recorded in a series of 5- to 10-min recordings each comprising eight to 20 trials.

\section{Stimulus manipulations}

The place fields of isolated complex-spike cells were initially mapped in baseline trials with all of the controlled cues arranged in the Standard configuration described earlier (recording room; Fig. 1). The distal and local cues were then either moved or removed to assess the cue or set of cues that influenced place field firing. Typically place fields were observed during the baseline trial, and the two sets of cues were altered in five types of trial to assess the influence of the cues as individual and relational stimuli on the place fields. (1) Double-rotation trials rotated the distal and local cue sets 90 degrees in opposite directions. This trial type determined whether units responded to one, the other, both, or neither of the stimulus sets. If a place field rotated with one of the stimulus sets, then we inferred that the unit was activated by at least one of the stimuli in that set. If a place field was disrupted in the double-rotation trials, then we inferred that the unit was influenced by some relationship among the stimuli in both sets. If a place field was unaffected by the double rotation, then we inferred that uncontrolled external or internal stimuli activated the unit. If clear unit activity but no place field was observed during the baseline trial, a double-rotation trial was given to test if place fields appeared. If a place field followed one of the cue sets in the double-rotation trial, then two types of subsequent tests attempted to identify the stimuli necessary for activating the unit. (2) Distal and (3) local scrambling trials interchanged the locations of the relevant cues in a way inconsistent with a rotation in the plane of the maze. If a unit responded to the relationships among one of the sets of cues, then scrambling those cues should disrupt the firing fields significantly. If, however, a unit responded to an individual cue, then the unit should fire in the same relationship to that individual cue as during standard conditions. During distal scrambling trials, the local cue set was rotated $90^{\circ}$ to determine if those stimuli now influenced unit activity. (4) Distal and (5) local cue deletion removed single cues. Distal cues were removed from the curtains, and arm inserts were replaced with plain wooden inserts painted flat black. The outcome from cue deletion and scrambling trials combined further distinguished relational from individual cue responses. Between trials, the rat remained connected to the recording apparatus and was placed in a closed, opaque cylinder on the maze center. This cylinder was rotated slowly by hand before the start of the next trial, when the rat was placed on a pseudorandomly chosen arm facing away from the maze center.

\section{Place Field Measures and Statistics}

To define place fields, the maze arena was divided into a $28 \times$ 28 array of $3 \times 3$-cm pixels. Firing rate was calculated by dividing the total number of spikes by the total amount of time spent in each pixel. If the rat visited the pixel fewer than 3 times or for less than $250 \mathrm{~ms}$, the firing there was considered undersampled and excluded from further analysis. Firing rates were calculated only if the rat was moving at a speed of $>2 \mathrm{~cm} / \mathrm{s}$. For each cell, a place field was defined as an area of three or more adjacent pixels with mean firing rates greater than $3 \times$ the grand mean rate (total spikes/total time in the maze), and an infield firing rate five times greater than the overall firing rate for that cell. Noncontiguous patches of adjacent pixels were defined at "subfields" of the overall place field. 
Six statistics assessed the spatial properties of the place cells: (1) The number of subfields assessed how many isolated patches contained significantly elevated firing rates. (2) The mean place field area was defined as the number of pixels (array $=28 \times 28$ ) within a subfield as described above. (3) The in-field firing rate was the highest rate within the field. (4) The directional tuning of the cell was defined as the ratio of the highest to lowest mean firing rate of the place field across eight horizontal heading directions. (5) Spatial selectivity was the $\log _{10}$ ratio of the mean in-field firing rate divided by the mean firing rate outside the place field. (6) A spatial correlation characterized similarities and differences in firing rate locations among baseline trials and assessed the spatial stability of the cell firing from one trial to the next (Shapiro et al., 1989; Hetherington and Shapiro, 1997). The spatial correlations calculated Pearson's r, which were then transformed to Fisher's Z for normal statistics.

Additional measures assessed the effects of cue manipulations on the place fields. In each case, firing field locations during baseline trials were compared to those observed during the probe trials. (1) Fixed place fields fired in the same arm, with the same longitudinal and radial position within the arm during probe trials as during baseline trials. Thus, if the cell fired within one-quarter of the arm length, and on the same side (left or right) of the arm as during the baseline trial, the field was considered fixed. (2) Rotated place fields fired in another arm in correspondence with the new location of a cue or set of cues, and within one-quarter arm length and the same side of the arm as observed in the baseline trial. Rotations were designated as following either the local or the distal cues. (3) New place fields fired in locations other than those that could be accounted for by baseline or rotated fields. New place fields could be produced by either spatially distinct firing patterns of a previously discriminated cell that did not meet the criteria for fixed or rotated place fields, or by the appearance of a place field for a previously silent or noisy cell (Thompson and Best, 1989). If after the manipulation some subfields were observed to meet the criteria for a fixed or rotated field but an additional subfield was observed in a new location, the overall place field was considered "new." (4) Finally, a cell with a place field recorded in the baseline condition could stop firing during a probe trial.

\section{Histology}

Each rat was given a lethal dose of Somnotol (1.3 mg/kg, i.p.), and current was delivered to each electrode $(30 \mu \mathrm{A}, 5 \mathrm{~s})$ to deposit iron ions at the site of the electrode tip. The rat was perfused intracardially with normal saline, followed by a $10 \%$ formalin, $4 \%$ potassium ferrocyanide, and $4 \%$ glacial acetic acid solution to fix the brain and mark the electrode tip positions by the Prussian Blue reaction (Gomori, 1936). Brains were stored in a $10 \%$ formalin solution, then transferred to a $30 \%$ sucrose, $10 \%$ formalin solution until the brains sank. Coronal sections $(50 \mu \mathrm{m})$ were cut on a cryostat and stained with formal-thionin to highlight cell layers and fiber tracts (Donovick, 1974).
RESULTS

\section{Histology and Unit Distribution}

The electrode track and final tip position was determined histologically for each rat and was used together with microdrive movements to assess the location of the recorded cells. Data were collected from 146 complex spike cells (73 CA1 and 73 CA3) recorded in ten rats $(\mathrm{n}=2,3,10,18,20,20,7,18,16,35)$. Of these cells, 137 were recorded in 35 simultaneously recorded twoto 11 -cell ensembles from seven rats, and the 12 remaining single cells were recorded from three other rats.

\section{Behavior}

The rats learned the lateral hypothalamus stimulation reward contingencies quickly and entered each arm of the maze once before repeating an arm entry typically within one to three trials. With experience, the rats adopted a regular response pattern and entered adjacent maze arms in a stereotyped sequence. The rats would occasionally reverse or otherwise alter the order of arm entries, yet typically avoided re-entering the arms before each had been visited. The rats often completed several trials and would then stop in a preferred arm and groom. This behavior increased during later trials. During maze manipulations, the "favorite arm" would often move in correspondence with place cell activity (see below).

\section{Electrophysiology}

\section{Normal place fields were recorded during baseline trials}

During the first baseline trial 120 of 146 recorded cells had place fields: 94 cells had one field, 22 had two subfields, four had three subfields, and 26 were either silent or noisy (Thompson and Best, 1989) and had no field. CA3 and CA1 place fields differed slightly. CA3 cells on average had $29 \%$ fewer subfields than CA1 cells and had place fields that were $32 \%$ more selective and $10 \%$ more stable than CA1 fields [subfields: $\mathrm{F}(1,144)=13.2$; selectivity: $\mathrm{F}(1,117)=13.7$; stability: $\mathrm{F}(1,116)=11.0 ; P<.001]$. These differences may be accounted for in part by either (a) the larger size and consequent better discrimination of CA3 cells, or (b) the fact that $\mathrm{CA} 3$ cells were recorded later in the experiment than the CA1 cells. However, CA3 and CA1 cells did not differ in place field area, mean firing rate, directional tuning, or spatial reliability (see Table 1).

\section{Place cells were influenced by the combined relationship among local and distal cues}

Double-rotation trials produced new representations in $43 \%$ of the place cells $(62 / 144)$, so that place fields either disappeared 
TABLE 1.

Characteristics of Place Fields Observed in Hippocampal Subfields CA1 and CA3

\begin{tabular}{lrrrrrrr}
\hline & Subfields* & Mean rate & Area & Directionality & Selectivity* & Reliability & Stability* \\
\hline CA1 & $1.2(0.08)$ & $3.1(0.42)$ & $8.06(0.59)$ & $13.9(4.1)$ & $1.9(0.07)$ & $0.57(0.03)$ & $0.59(0.04)$ \\
CA3 & $0.84(0.07)$ & $3.4(0.44)$ & $7.6(0.66)$ & $14.3(3.6)$ & $2.5(0.10)$ & $0.51(0.07)$ & $0.65(0.05)$ \\
\hline
\end{tabular}

${ }^{*} P<0.001$ between layers.

( $21 \%$ ) or appeared in locations that could not be accounted for by the movement of a field with respect to any cue or cue constellation $(22 \%)$. This "remapping" response to double rotation was the most common occurrence in double rotation trials and suggests that rats encoded the relationship among local and distal stimuli (Fig 2). Occasionally a new field would appear only during the double-rotation trial, and the field would disappear in subsequent baseline trials (Fig. 2). In other cases, a field would appear or move to a new location during the double-rotation trial and then return to its original location during subsequent baseline trials. Other place fields moved or disappeared during the double-rotation trial and did not return when the rat was placed in the standard configuration. In some cases it was possible to identify the relationship between local and distal cues that was encoded during a probe trial (Fig. 2). Each of these response types occurred occasionally within single ensembles of simultaneously recorded cells (Tanila et al., 1997a).

The persistence of new fields during and after double-rotation trials was not sufficient to significantly reduce the spatial correlation between the baseline trials flanking the double rotation ( $\mathrm{r} \pm \mathrm{SEM}$ : new representation, $0.88 \pm 0.13$; no change, $0.94 \pm 0.28$; rotation with distal cues, $0.94 \pm 0.17$; rotation with local cues, $0.96 \pm 0.29)$.

\section{Place cells respond to a hierarchy of cue configurations and individual distal stimuli}

During double rotation trials, $28 \%(41 / 144)$ of the place fields rotated with the constellation of distal cues (Fig. 3). To determine the relative influence of stimulus relationships and individual cues, 31/41 cells were tested in distal cue scrambling trials, and $37 / 41$ were tested in distal cue removal trials. Only a small minority of these cells depended upon relationships among the distal cues: Only 10\% (3/31) of the cells that followed the constellation of distal stimuli during double rotation trials stopped firing altogether during distal scrambling trials. In contrast, $42 \%(13 / 31)$ of the cells followed single distal cues. When single distal stimuli were removed, however, 84\% (31/37) of the cells were unaffected (Fig. 3), only $11 \%$ (4/37) stopped firing, and 5\% (2/37) appeared to rotate toward another distal cue. Thus, the individual distal stimuli were often sufficient, but not necessary, for place field activity.
Furthermore, $49 \%$ of the cells that rotated with distal cues during double-rotation trials switched to follow local or uncontrolled cues during distal scrambling trials (Fig. 4). Thus, of the cells that followed the distal cues during double-rotation trials, nearly half switched responses during distal cue scrambling trials, so that $39 \%$ (12/31) followed the rotated local cues (Fig. 4) and another $10 \%(3 / 31)$ were unchanged, indicating that they now fired with respect to uncontrolled stimuli. The switched responses from distal to local or to uncontrolled cues suggest that these hippocampal neurons encoded a hierarchical representation of the different types of stimuli in the environment.

\section{Local cues influenced place fields}

A hierarchy of representations was also suggested by the effects of altering local cues. During double-rotation trials, 15\% (22/ 144) of the place fields rotated with local cues (Fig. 5). To determine the relative influence of stimulus relationships and individual local cues, $21 / 22$ cells were tested in local cue scrambling trials, and 15/22 were tested in local cue removal trials. The majority of the cells $(57 \% ; 12 / 21)$ were unaffected by local cue scrambling, indicating that they now fired with respect to distal or uncontrolled stimuli (Fig. 5). Twenty-four percent (5/21) of the cells stopped firing during local cue scrambling trials, and one cell fired in a new location altogether, each of these response types indicating that the cells responded to relationships among local cues. Only $10 \%(2 / 21)$ of the cells followed a single local cue. As in the case of removing single distal cues, removing single local cues rarely altered cell firing. Only $1 / 15$ cells stopped firing after a single local cue was removed, and $2 / 15$ cells appeared to follow distal stimuli. Most of the cells $(80 \% ; 12 / 15)$ were unchanged (Fig. 5). Thus, most place fields that rotated with the local cues during double-rotation trials tended to switch to follow distal or uncontrolled cues when the relationship among local stimuli were changed or individual local cues were removed.

Eleven CA1 and 11 CA3 cells were examined with local stimulus manipulations. All nine of the cells that responded to local cue scrambling were CA3 cells, and none were CA1 cells. Only two CA3 cells were unaffected by local cue scrambling $\left(\chi^{2}(1)=11.73, P<.0006\right)$. This effect, however, may have been influenced by the rats' experience with cue scrambling trials, 

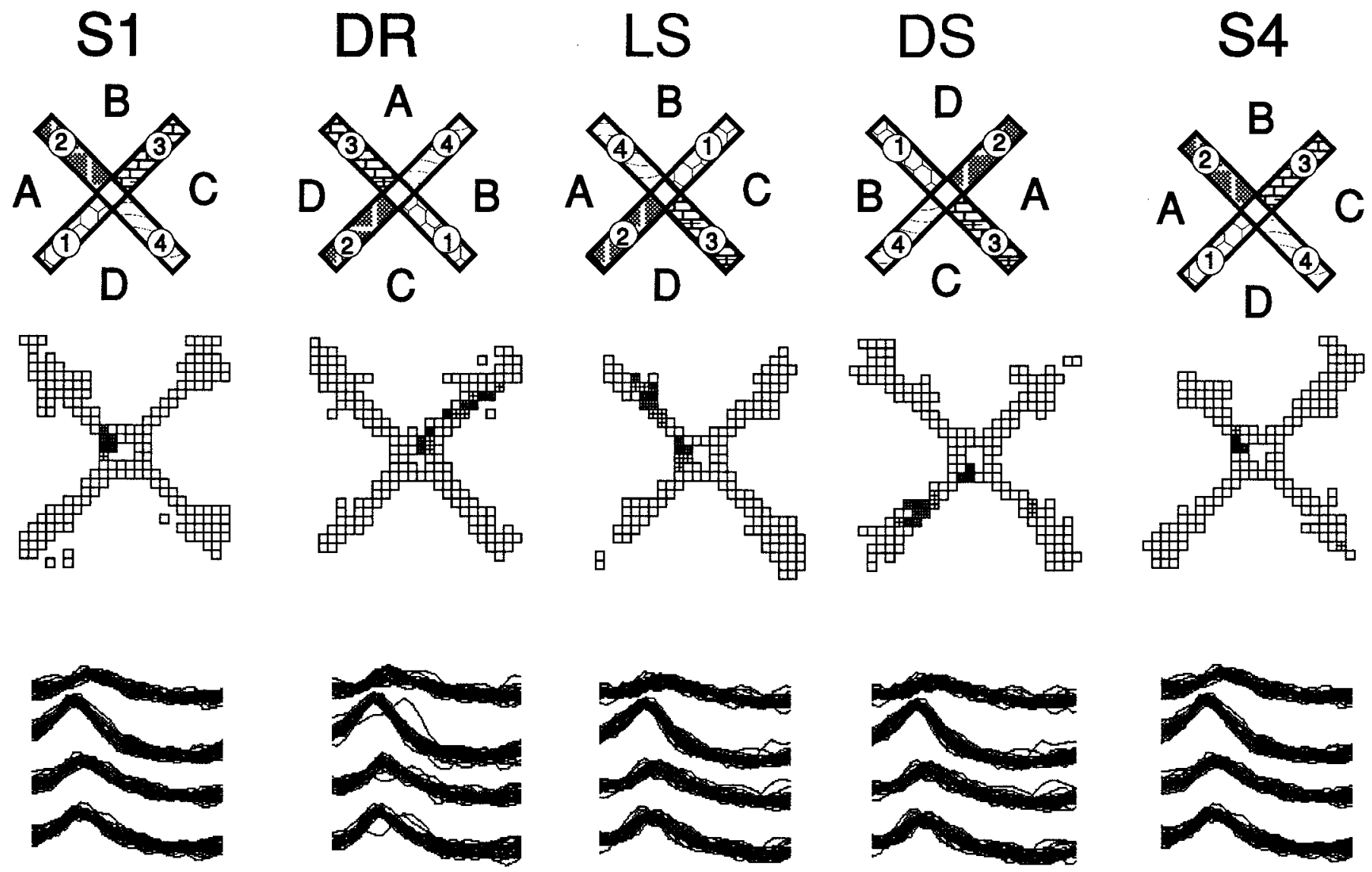

FIGURE 2. Double-rotation trials produced new representations. This cell fired reliably on the left-hand side of the central platform during standard trials (S1, S4). During double-rotation trials, the original subfield rotated with the distal cues, and the cell developed a new subfield on arm 4 to the right of distal cue A and to the left of B (DR). The stimuli encoded by the new subfield during the double-rotation trial was determined by the probe tests to be the conjoint presence of distal cue B to the rat's left and the local cues on arm 4. In the local cue scrambling trial (LS), the original subfield appeared in its original location, but the new sub- field rotated and again appeared to follow arm 4 between distal cues A and B. In the distal cue scrambling trial (DS), the local cues were rotated clockwise; the original (platform) subfield again appeared to the left of distal stimulus B, and the new subfield again appeared on arm 4. Because distal cues $B$ and $C$ now flanked the arm, the new subfield is shown to respond to the conjoint presence of distal cue $\mathrm{B}$ to the rat's left and the local cues on arm 4. This result also shows that different subfields of one cell can encode different relationships among stimuli. because most CA1 cells were recorded before CA3 cells during the experiment. An analysis of variance (ANOVA) predicting the effect of cue scrambling by cell layer using trial number as a covariate showed a significant effect of trial, but not of layer $(\mathrm{F}(1$, 18): layer $=0.3, \mathrm{~ns}$; trial $=6.4, P<.05)$.

The place cells controlled by local cues during double-rotation trials were likely to either remain unchanged $(57 \%)$ or to remap (29\%) during stimulus scrambling, and were unlikely to follow single cues $(10 \%)$ or to switch to follow distal cues $(5 \%)$. In contrast, the place fields controlled by distal cues during doublerotation trials were most likely to either follow single distal cues $(42 \%)$ or to switch to follow local cues $(38 \%)$ when the distal stimuli were scrambled, and were unlikely to remain unchanged $(10 \%)$ or remap $(10 \%)$. Thus, place cells controlled by the different cue sets during the double-rotation trial also responded differently during cue scrambling trials $\left(\chi^{2}(3)=22.7, P<.0001\right)$.

Taken together, the effects of double-rotation trials and cue removal and scrambling trials suggest that hippocampal neurons respond to a hierarchy of available stimuli. If the predominance of responses is interpreted as evidence of hierarchy order, then place cells encode the relationships among available local and distal salient stimuli first, encode individual distal stimuli next, and encode local stimuli last. The logical intersection of local and distal stimuli can be viewed as providing the highest and most robust information content (certainty) about environmental content and location, with each stimulus subset providing successively less predictive information. Thus, the hippocampus appears to encode redundant environmental information with efficiency and can recode this information flexibly when redundancies dissociate. 

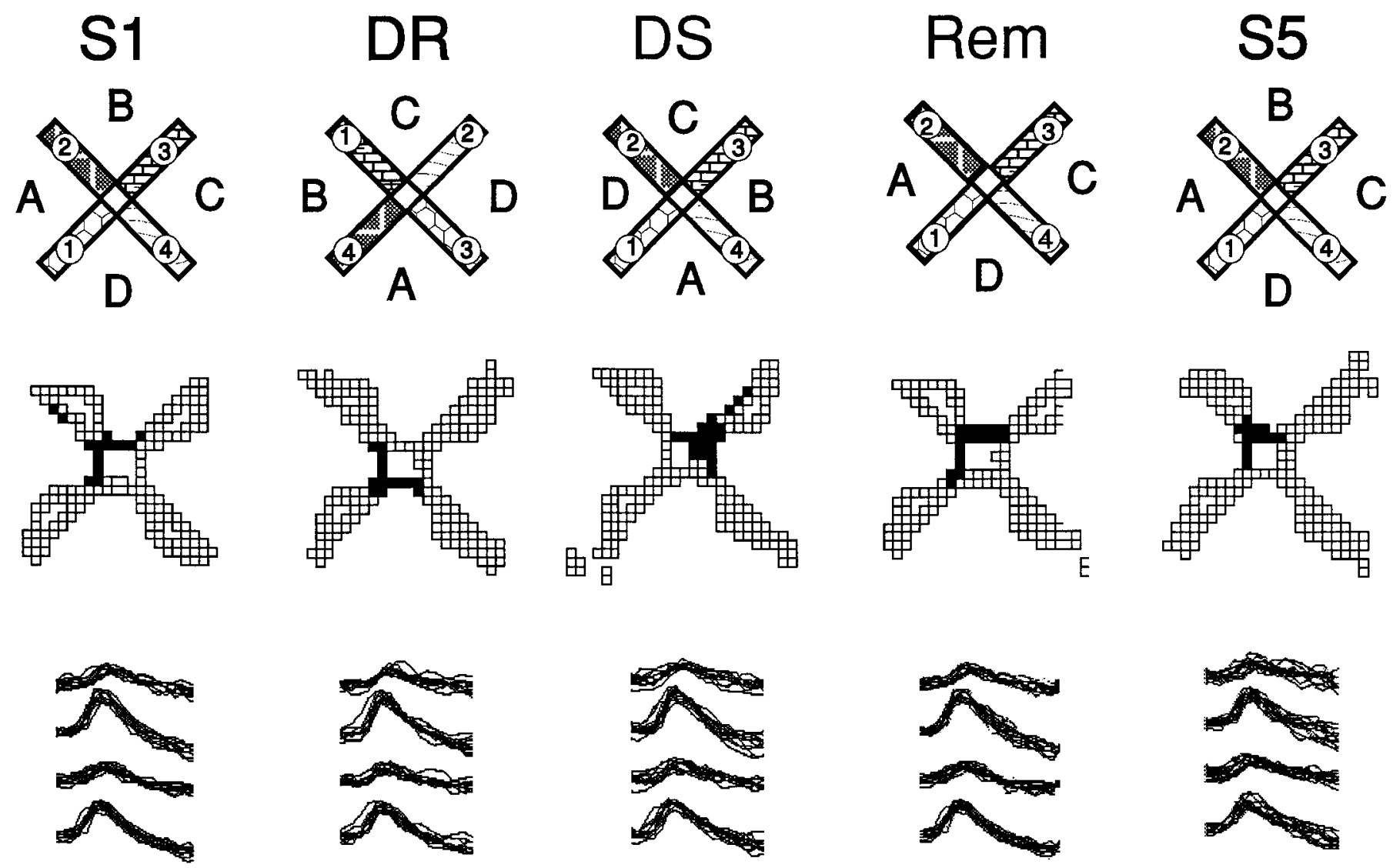

FIGURE 3. Fields that rotate with a single distal cue can persist after its removal. The place field appeared reliably on the upper and left sides of the central platform during standard trials (S1, S5). The place field rotated anticlockwise with the distal cues during the double-rotation trail (DR), and fired in a location consistent with the placement of distal stimulus B in the distal scrambling trial (DS). When distal stimulus B was removed, however, the field was unchanged (Rem). Significant firing is shown by the solid black squares.

\section{Remembered stimuli influenced place fields}

About 12\% (13/144) of place cells were stable during doublerotation trials and thus were not influenced by either distal or local controlled cues. This stability can be attributed either to the non-controlled cues in the environment (e.g., the noises from the recording apparatus) or to stimuli internal to the animals (e.g., spatial working memory). In at least one case, an ensemble of four place cells was controlled by the transient location of the experimenter who was in the recording chamber only between recording trials (Fig. 6). In this case, the experimenter stood $90^{\circ}$ $\mathrm{CCW}$ in a SW location before leaving the recording room rather than in the NW. All of the place fields rotated $90^{\circ} \mathrm{CCW}$, and rotated back in subsequent trials when the experimenter stood in the NW. These results are consistent with previous reports that remembered stimuli can control place field locations (O'Keefe and Speakman, 1987; Quirk et al., 1990) and suggest that memory can override perceptual influences on hippocampal representations.

\section{Repeated double-rotation trials altered the encoding of that environment}

During double-rotation trials at the start of this experiment, we observed that place fields were rarely unchanged (6\%), but usually rotated with either the distal $(47 \%)$ or the local $(16 \%)$ cues, or fired in new patterns (31\%). Later in the experiment, however, the proportion of place fields that were either unchanged or reflected new representations during double-rotation trials increased dramatically $(70 \%)$, while the proportion that followed distal stimuli was greatly reduced. The proportion following local stimuli was unchanged. Thus, the distribution of responses to double rotation changed significantly $\left(\chi^{2}(6)=21.46, P<.001\right)$ with increased exposure to both situations (Fig. 7). Together with the effects of remembered stimuli described above, these results suggest that the rats learned to encode the organization of stimuli in the doublerotation condition as a distinct representation of the environment, but one that often was related to the standard environment, in that a proportion of the cells maintained representations of subsets 

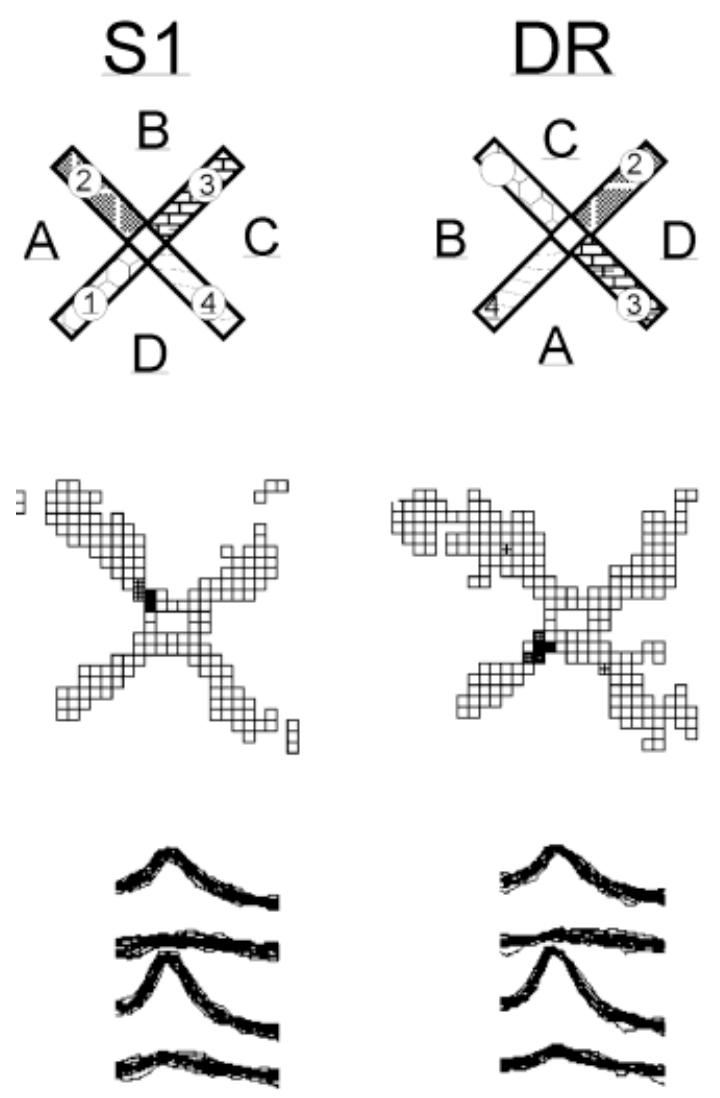

FIGURE 4. Switching from distal to local cues. The place field fired consistently near the central platform in the upper left-hand arm during standard trials (S1 and S4). The field followed the anticlockwise rotation of the distal cues during the double-rotation trial (DR), and was unaffected by local scrambling (LS). However,

of the cues across the two conditions even after extensive experience in both.

\section{Overlap Among Place Fields}

In previous experiments using single-ended recording methods, we (Eichenbaum et al, 1989b) and others (e.g. Hampson et al, 1996; Muller et al., 1987) have observed that cells recorded in local CA regions often had place fields that were closer and more overlapped than would be expected by chance. We have described the same results using stereotrodes (Hetherington et al., 1997), and again observed the same pattern in the present experiment using tetrodes (Fig. 8). Many of the ensembles recorded here included cells with overlapping place fields. Thus, while the hippocampus is not organized anatomically in a spatiotopic map of the environment, the areas of the environment containing especially salient information are overrepresented compared to others (see Hetherington et al., 1997), and the representational heterogeneity is reflected within local groups of hippocampal neurons. The representational heterogeneity also reflects the hierarchy of information encoded by place cells in that the best
DS
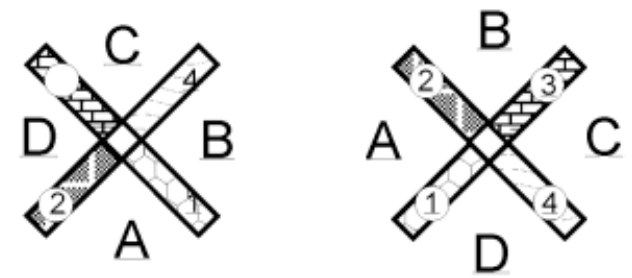

S4

B

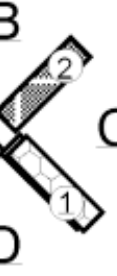

A
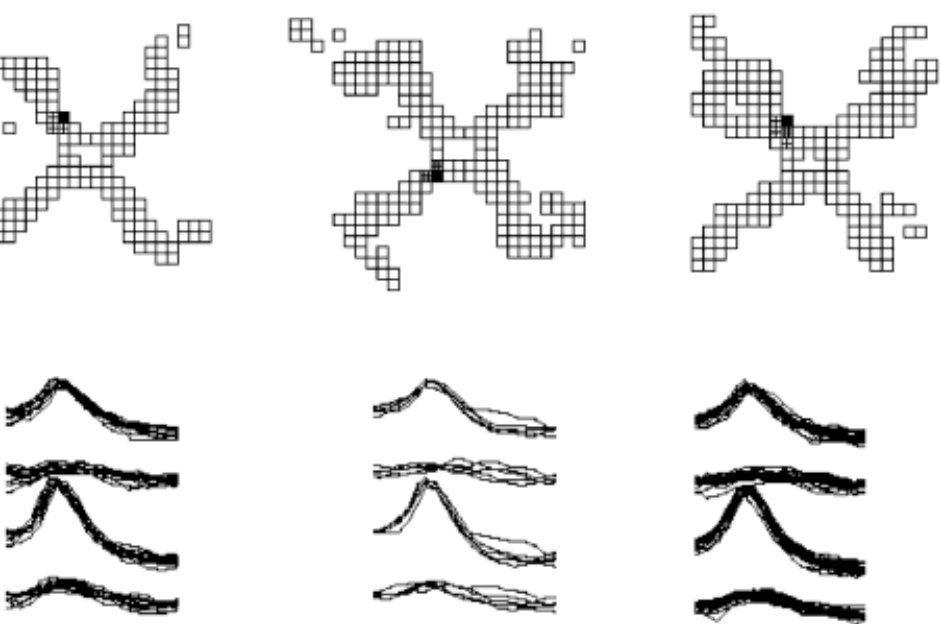

when the distal stimuli were scrambled, the cell fired at the start of arm 2, the physical arm that held the place field during the standard trials. Thus, the stimuli encoded by the cell switched from distal to local stimuli during the distal scrambling trial.

\section{DISCUSSION}

Hippocampal place cells were recorded as rats explored a four-arm radial maze with controlled distal and local stimuli. Systematic manipulations of individual cues and the relationships among the cues revealed that hippocampal neurons encoded the relationship between the cue sets, relationships among cues within a stimulus set, and individual distal cues. Double-rotation trials, which maintained stimulus relationships within distal and local cue sets, but altered the relationship between them, often changed the responses of the sampled neural population and produced new representations. After repeated double-rotation trials, the incidence of new representations increased, and the 

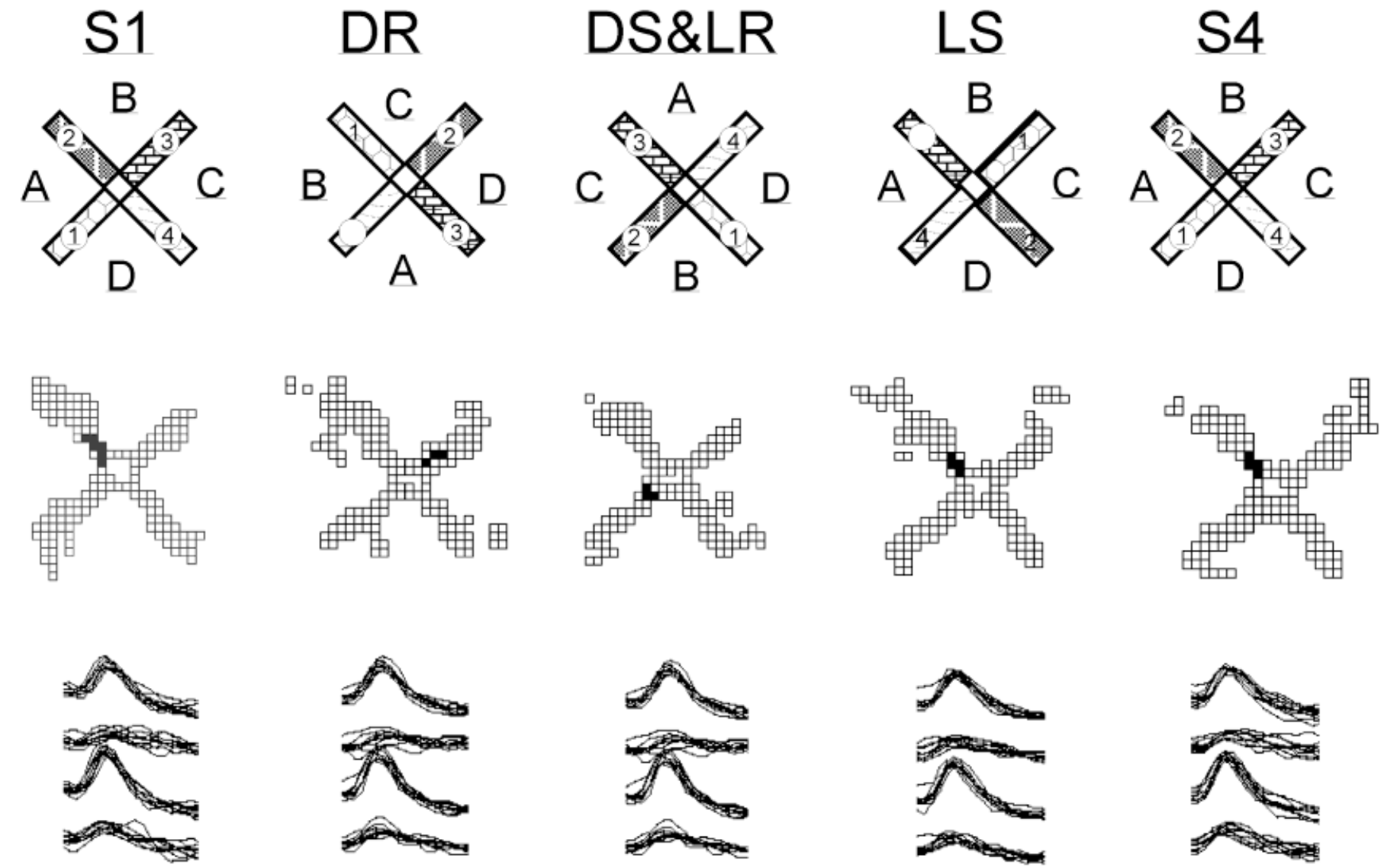

FIGURE 5. Switching from local to distal cues. The place field fired in the upper left arm during standard trials (S1 and S4). The place field followed the local cues during both the double-rotation trial (DR) and the distal scramble trial with local cues rotated anticlockwise (DS \& LR). In each of these trials, the best predictor of

the field's location was local cue 2. However, during the local scramble trial (LS), the field remained in the same room location as during the standard trials (S1 and S4). Thus, the stimuli encoded by the cell switched from local to distal stimuli during the local scrambling trial.

likelihood of a simple rotation with one of the cue sets diminished. Less often, cells had fields that followed the set of distal stimuli. These fields often followed a single cue when the stimulus constellation was scrambled, but kept firing when the relevant stimulus was removed. Yet more rarely, cells had fields that followed the set of local stimuli during double-rotation trials. These fields most often remained fixed when the local stimuli were scrambled and persisted when single local cues were removed. Together, the results show that individual hippocampal neurons encode different subsets of the multiple spatial relationships that exist among the prominent environmental stimuli. Because the neurons respond in a flexible, yet non-random fashion, we propose that hippocampal cells respond hierarchically to the inputs derived from a wide variety of environmental cues.

\section{Individual hippocampal neurons encode manifold relationships among stimuli}

The world includes many sources of information that may be crucial for an animal's survival. To be useful to an organism with limited information processing capacity, however, this myriad information must be limited and organized. Cognitive maps provide an organizational framework within which vast amounts of information can be encoded (O'Keefe and Nadel, 1978). The original formulation of the cognitive mapping theory suggested that the relationships among distal stimuli were most useful for constructing a spatial map which was reflected in the activity of hippocampal place cells (O'Keefe and Nadel, 1978). More recent studies have shown that hippocampal neurons encode many other types of stimuli (e.g., Eichenbaum et al., 1987, 1988; Wiener et al., 1989; Hampson et al., 1993; Young et al., 1994a) and that the hippocampus is required for encoding non-spatial relationships (Bunsey and Eichenbaum, 1996; Dusek and Eichenbaum, 1997).

The present data show that individual hippocampal neurons respond flexibly to more than one configuration of the same stimuli. For many cells, while both the shape and local and radial positions of the place field was maintained after cue manipulations, the cues that most influenced the angular position of single place cells switched among the controlled stimuli after the topological organization of these stimuli were altered. The 

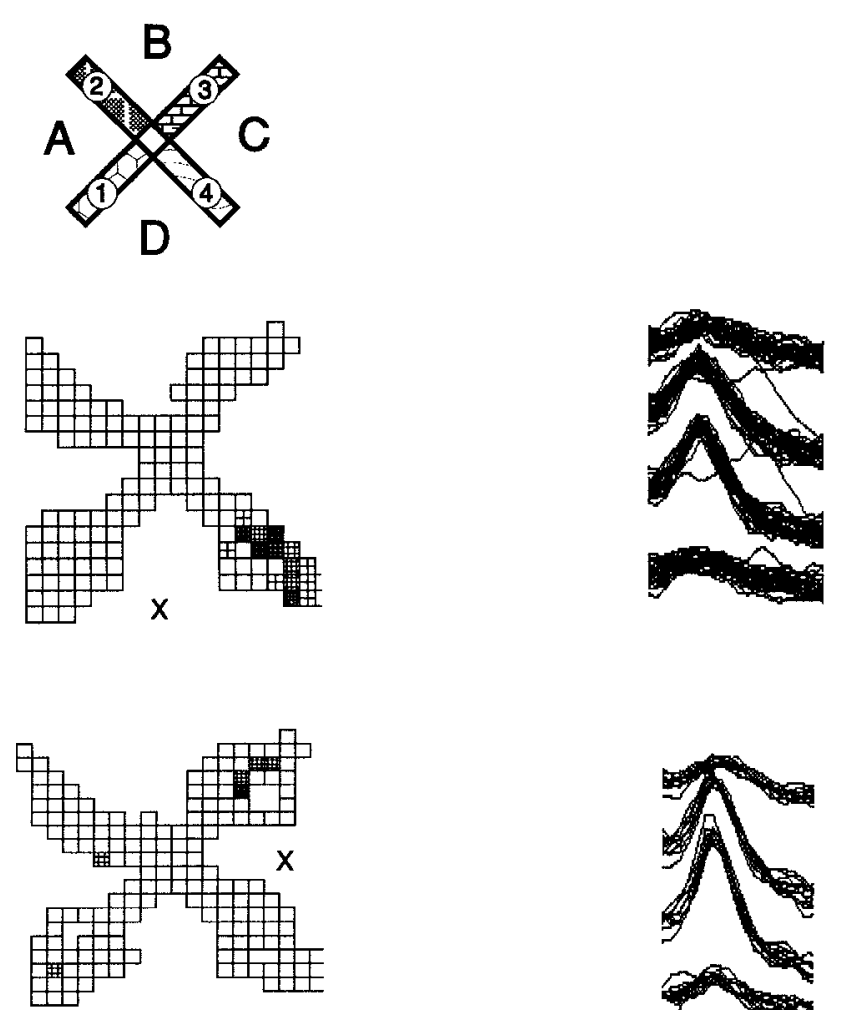

日日
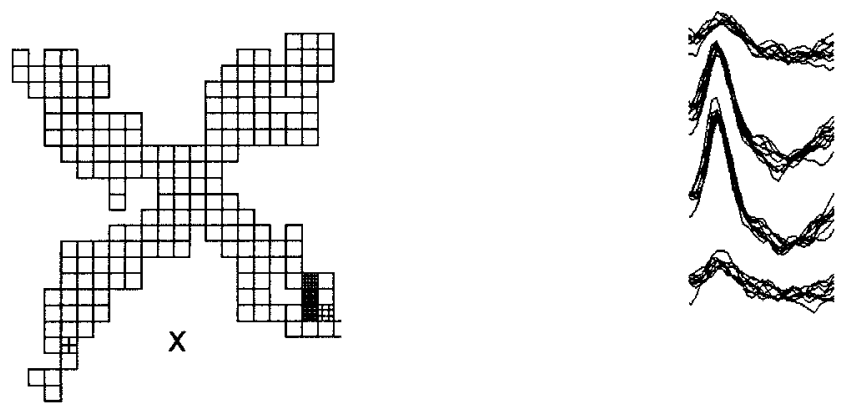

FIGURE 6. Memory field. During three consecutive trials, the cell fired in the arm anticlockwise from the experimenter's location when he removed the rat from its opaque container. Thus, the cell (and three others recorded simultaneously) encoded a remembered location despite the presence of salient local and distal cues.

switching suggests that multiple, functional input sets determine the activity of place cells, but that only one set controls the field at any one time. For many cells, while both the shape and local and radial positions of the place field was maintained after cue manipulations, the cues that most influenced the angular position of single place cells switched among the controlled stimuli after the topological organization of these stimuli were altered.

\section{Response preference and predominance implies a hierarchy}

Although the hippocampus may indeed encode spatial cues, the "map" of places uses cues that are organized hierarchically. Here, hierarchy is defined as the systematic ranking of place field responses to different types of stimuli. The data show clearly that different stimuli influence individual hippocampal cells to different extents. The hierarchical encoding of stimuli is proposed because the stimulus or set of stimuli that controlled a place field changed from a "preferred" to an "alterative" set when the organization or the content of the environment changed. Furthermore, different types of stimuli were more or less likely to control the place cells: most cells encoded relationships among both local and distal cue sets, fewer cells responded to relationships among distal cues, and yet fewer encoded individual distal cues or relationships among local cues. This response hierarchy is not the same as a multilevel classification system with distinct levels; rather, different stimulus combinations have an orderly influence on each place cell, perhaps one that emerges from competitive learning (described below).

\section{Hippocampal neuronal responses switched to encode different combinations of stimuli}

Individual hippocampal cells have multiple sensory/behavioral correlates that can be reliably elicited by different sensory inputs, behavioral contingencies, or overt behavior patterns (Kubie and Ranck, 1983; Wiener et al., 1989; Eichenbaum, 1996). The present results extend these findings by showing that individual cells respond differently to altered spatial organizations of the same stimuli while overt behavior is constant. First, $49 \%$ of the cells that originally rotated with the constellation of distal cues switched to follow local or uncontrolled cues when the topological relationship among the stimuli was changed. Furthermore, $40 \%$ of the neurons that originally rotated with the constellation of distal cues followed one of these cues when the topological relationship among them was changed during cue scrambling trials. These results by themselves suggest that some hippocampal units encode individual stimuli. Paradoxically, however, $83 \%$ of these cells were not affected when the cue that was followed was subsequently removed (cf. O'Keefe et al., 1978a; Hetherington and Shapiro, 1997).

The persistence of place fields after the removal of single cues has often been observed (O'Keefe and Dostrovsky, 1971; O'Keefe and Conway, 1978; O'Keefe, 1979; Muller and Kubie, 1987). This resistance to cue removal has been linked to pattern completion, a property found in many network models of place cells that compute place fields as a function of weighted inputs, e.g., derived from the distance to one identified stimulus (e.g., Shapiro and Hetherington, 1993). The crucial observation here is the switched response: Cells with fields that followed the constellation of distal stimuli and "ignored" the location of local and uncontrolled stimuli during double-rotation trials switched to follow the previously irrelevant stimuli when the topology of the distal cues was changed. This switching differs from pattern completion and suggests that the persistence of place fields after cue removal may actually reflect switching. 


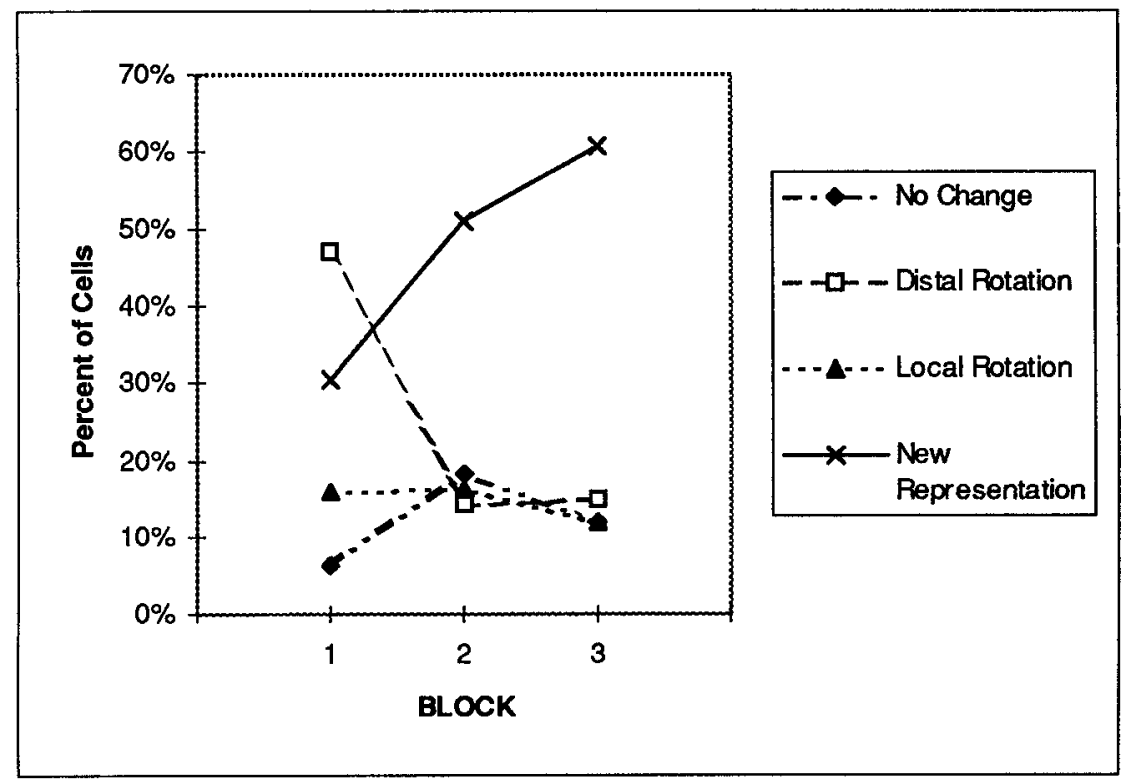

FIGURE 7. The effects of double-rotation trials changed with repetition. The most common response of place fields during the first block of five double-rotation trials was a rotation with distal stimuli.

\section{Competition among inputs to hippocampal cells: a model of a switching network}

Individual hippocampal neurons participate in different representations across different environments and tasks (e.g. Kubie et al., 1983; Muller et al., 1987a; Wiener et al., 1989). This multiplicity of responses may be accounted for by the small number of input axons required to fire a (e.g.) CA1 cell, estimated to be $\sim 1 \%$ (Andersen, 1990), and the implication that many different input subsets could independently and reliably trigger action potentials. Environments containing different stimuli or imposing different behavioral contingencies could therefore activate different subsets of hippocampal cell afferents. In the present experiment, however, neither the behavioral contingencies nor the stimulus content of the environment changed. Rather, only the topological relationships among the stimuli was altered. The results suggest that hippocampal cells are activated by multiple sets of conjoint inputs that each encode separate stimulus relationships.

At a psychological level, the set of conjoint distances to local and distal cues are powerful predictors of locations, with each stimulus providing converging and correlated evidence verifying that the animal occupies a given location. At a physiological level, the input from the neural inputs representing each of the cues converges onto the same cell at the same time, so with appropriate timing, correlated inputs would produce associative LTP.

Switching can be accounted for by a competitive interaction among active inputs (Fig. 9). Functionally independent sets of excitatory inputs to each hippocampal cell may compete via feedforward inhibition. When information encoding one of these subsets is altered (e.g. by cue scrambling or cue removal), the net
Subsequently, rotation with distal stimuli decreased, and the probability of a new representation increased markedly. (See text for statistics.)

input from that subset is reduced while other active inputs are released from inhibition. Consequently, after these principal stimuli are removed, the remaining ones may be disinhibited and a new representation (i.e. sensory or behavioral correlate) can emerge (Fig. 9). As in "winner take all" competitive learning networks, multiple excitatory inputs converge on each cell. The excitatory inputs to each hippocampal cell mutually inhibit one another, and the most powerful input sets control the activity of the cell. Competitive learning, as reflected by LTP, ensures that the cues that provide the best predictors of location (i.e. are most highly correlated with environmental regularities) will gain most control over the cell through enhanced synaptic strength. If the input set representing the highest order relationships between local and distal cues is disrupted (e.g. in double rotation trials), then second-order inputs (e.g. relationships among distal stimuli only) are disinhibited and the cell responds to the distal cues alone. If the distal stimuli are scrambled, then the input encoding the relationships among the distal cues is disrupted, the inputs from the single cue with strongest input to the cell is released and activates the cell, and the field follows that cue. When this single stimulus is removed, remaining inputs are disinhibited. If sufficient numbers of familiar stimuli are disrupted, the hippocampus may respond to an entirely different set of stimuli, and a "new representation" can emerge. This model provides a simple account of the changes in unit activity that have previously been attributed to multiple reference frames (Gothard et al., 1996b).

From this view, the response hierarchy reflects a competition among inputs with different strengths. Presumably the strength of a given input is determined by the same mechanisms as those underlying LTP. Thus, the highest-order inputs encode the 

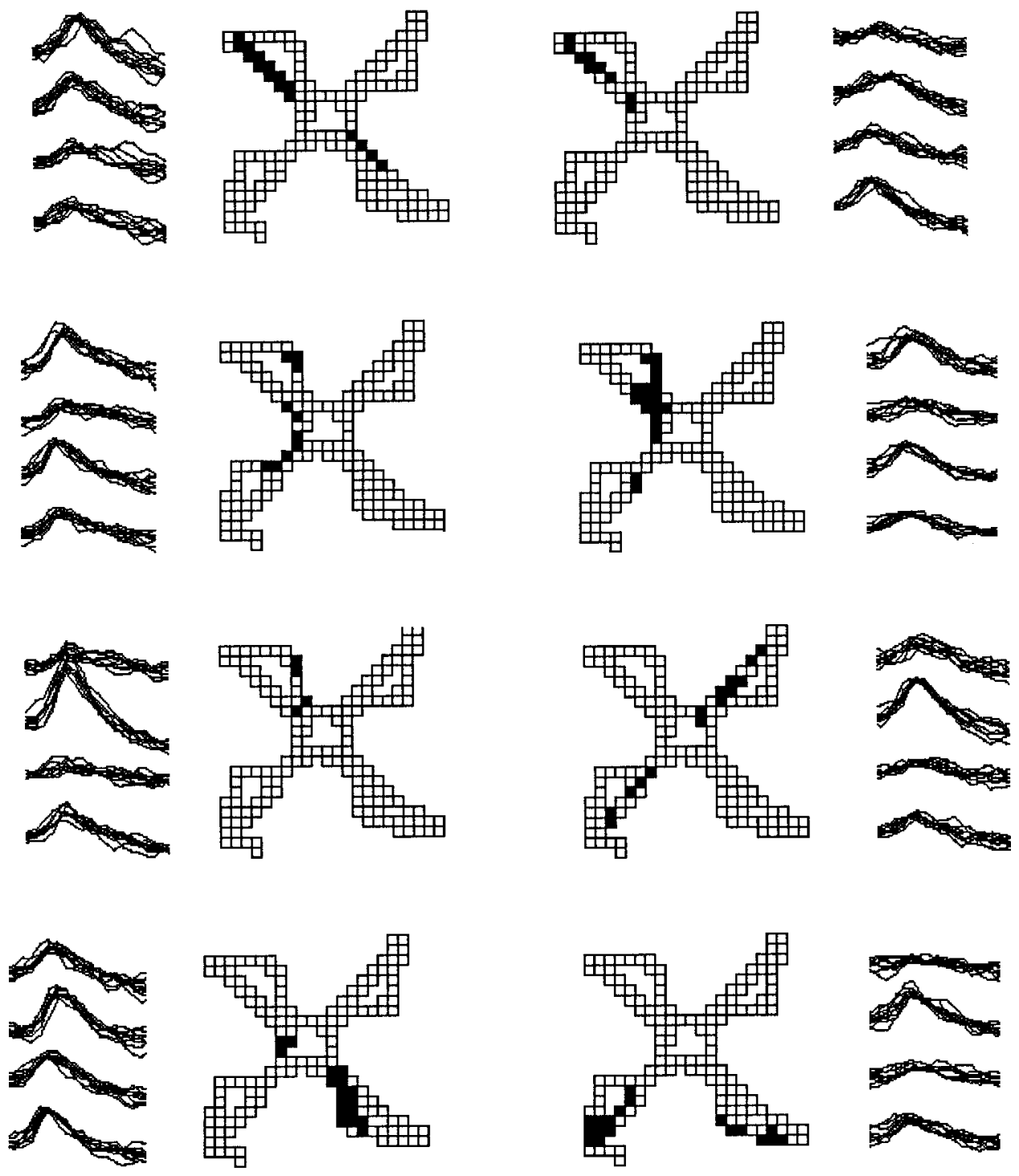

FIGURE 8. Within ensembles of simultaneously recorded cells, place fields were distributed heterogeneously and overlapped with one another. As illustrated by this ensemble of eight cells and 14 subfields, five cells had nine overlapping fields on the northwest arm and the adjacent maze center, three cells had three fields in the southeast arm of which two overlapped, four cells had four fields in the southwest arm, and only one cell had a field in the northeast arm. The fields were distributed over much of the maze surface, but the distribution was heterogeneous.

conjoint relationships among stimuli, such as distances to a subset of available stimuli. The available stimuli include those derived from local, multimodal "views" (Gothard et al., 1996b) as well as from recurrent activation of the CA3 network that may represent recently experienced stimuli and other past associations (Hetherington et al., 1993a; Hetherington et al., 1993b; Muller et al., 1996). Place field activity therefore represents the available stimulus relationships together with remembered ones. The representation is local in the sense that the cells encode the information closely related to the available stimuli. Rather than encoding a reference frame, the active set of cells encode the locally available stimuli (together with recurrent input that encodes neighboring, associated locations). The problem of linking reference frames is solved because the activated representation is derived from locally available stimuli, which in turn activate associated representations through the CA3 association pathway (Hetherington \& Shapiro, 1997; Muller, Stead, \& Pach, 1997). Thus, the doorway that from a distance forms an important cue for navigating within a room helps, as it looms larger, to activate the representation of the coming hallway.

\section{Influence of single distal cues}

Removing single cues from the set that controlled place fields altered between 5\% (local cues) and 16\% (distal cues) of the fields. This observed occurrence of single cue control is similar to that 


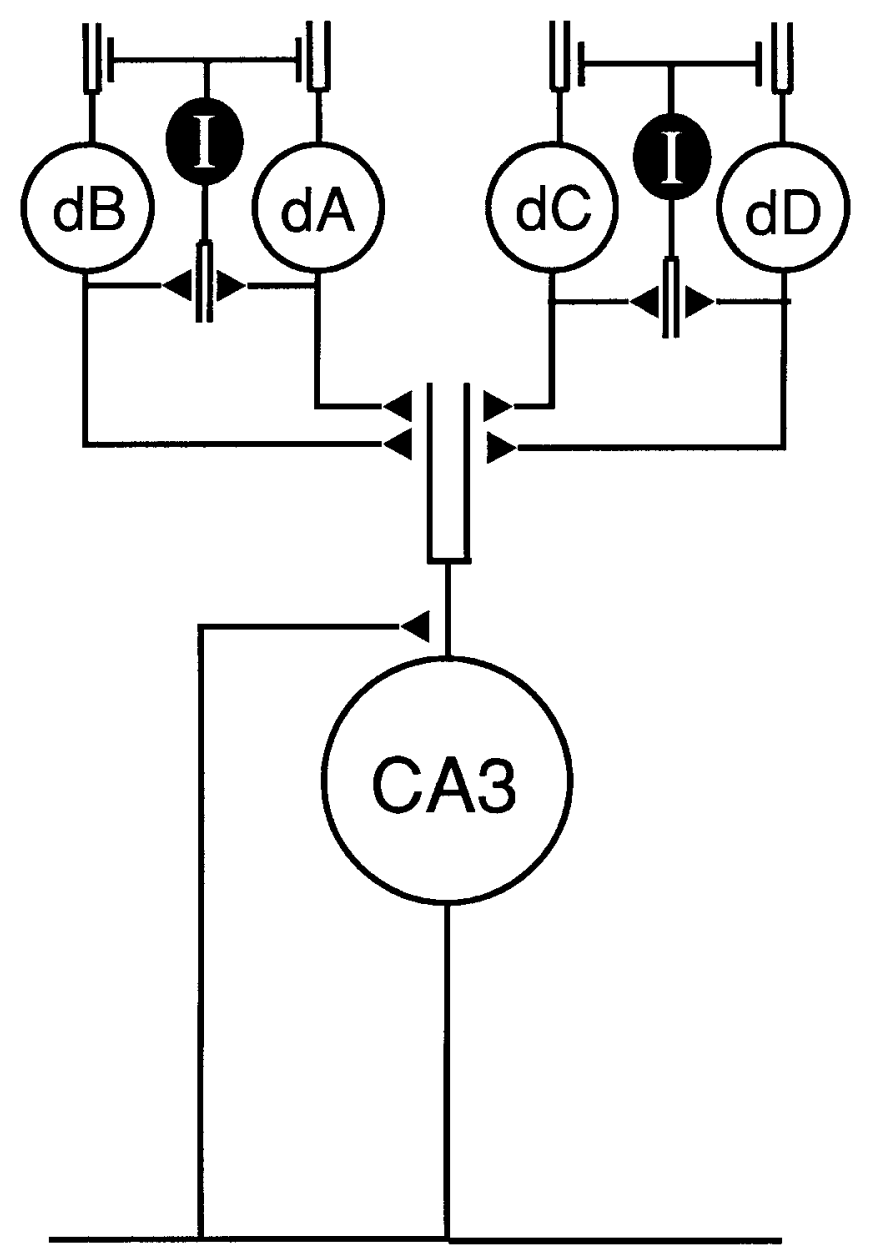

FIGURE 9. A model of competitive inputs that can account for switched encoding by hippocampal place fields. In this model, each input (small circle) represents a property of an identified stimulus (e.g., allocentric distance to a local cue). The strength of an input to a hippocampal cell (large circle) is determined by a competitive learning rule (e.g., as reflected in LTP), so that consistently effective inputs gain connection strength. Inputs combine to excite the hippocampal neuron, but each also inhibits the other inputs, so that changing stimulus relationships can disinhibit remaining inputs and produce a switched response. Place cells are connected to one another via recurrent pathways in the dentate and CA3, and this recurrent connection provides a simple mechanism for associating neural representations and encoding working memory (see Muller et al., 1996; Hetherington and Shapiro, 1993a-c, 1997).

found in prior studies. In O'Keefe and Conway's (1978) original report, removing single distal cues altered three of eight (37\%) hippocampal units in an open maze (O'Keefe and Conway, 1978). More recent studies have examined quantitative changes to place fields after single cue removal. Hetherington and Shapiro (1997) reported that removing single cues reduced the spatial information content of place cells an average of $18 \%$ and altered the firing rate and area of place fields in a distance-dependent manner (Hetherington and Shapiro, 1997). Muller and Kubie (1987) found that removing the sole cue in a cylindrical recording chamber typically produced no fundamental change in place field location but did reduce spatial coherence defined as a twodimensional autocorrelation. O'Keefe and Burgess (1996) demonstrated that place field size and shape can be stretched or split when the length or width of the recording chamber is expanded (O'Keefe and Burgess, 1996). Fenton and Muller (1996) reported that in a cylinder containing two cue cards each on the wall of the cylinder, expanding or contracting the angle between two cards had different effects on place fields depending upon the field's relative distance to the cues. Place fields near one card typically moved with that card. Place fields located about midway between the two cards typically stretched when the cue cards were separated, and were compressed when the cards were moved closer together. As in the studies above, removing either one of the cue cards had little effect on the place fields (Fenton and Muller, 1996).

The major difference between the prior studies and the present results is the switching of control from one cue or set of cues to another: Cells with fields that followed the constellation of distal stimuli and "ignored" the location of local and uncontrolled stimuli switched to following these previously irrelevant stimuli when the topology of the distal cues was changed.

\section{Influence of Local Cues}

In the present experiment, prominent distal and local stimuli both strongly influenced the firing patterns of hippocampal cells. One indication of the local cues' influence was shown in double rotation trials. In most studies, the salience of local stimuli is reduced deliberately, and rotating the configuration of distal stimuli is sufficient to produce a rotation of the vast majority of place fields (e.g., 100\% in Hetherington and Shapiro, 1997). In the present study, only $28 \%$ of the cells followed the distal cues during rotation, and $15 \%$ followed the local cues during the double-rotation trial. These data, together with the small proportion of cells left unchanged in double-rotation trials, suggest that the hippocampal cells were strongly influenced by the controlled stimuli. In the presence of salient local cues, distal stimuli exerted less than the usual amount of influence over place fields. Perhaps because the distal cues comprised a smaller proportion of the information available in the environment, they had less influence than in prior studies.

An important implication of these results is that the difference between local and distal stimuli may reflect more on the experimenter's perspective than that of the rat or the rat's hippocampus. Both distal and local cues provide potentially important signals for guiding successful behavior, and survival would likely be enhanced for encoding both in memory. Furthermore, the assignment of a "local" label to maze cues is somewhat arbitrary, because the same cues (like "distal" cues) are local when the rat is very near them, and distal when the rat is at a distance from them. Thus, the information provided by visual and olfactory distinctions among the arms may have been detectable from a distance, whereas the tactile information was truly localized to the arms per se. 
The majority (57\%) of cells with place fields that followed the local cues during double-rotation trials were not affected by either cue scrambling, which altered the topological relationship among these cues, or by the deletion of a single cue. Rather, the same cells that were influenced by local cues during double-rotation trials appeared to respond to uncontrolled internal or external stimuli during cue scrambling and cue removal trials. Thus, the cells' activity was not locked to any one stimulus or set of stimuli, but rather encoded manifold relationships among the cues that were salient in the environment.

\section{Place Field Responses Changed With Experience in Altered and New Environments}

Double rotation trials often (42\% cells; $40 \%$ ensembles) produced a dramatic remapping of hippocampal place fields. The appearance of these new representations demonstrates that the cells encoded the relationships between the distal and local cue sets. Another $40 \%$ of the cells continued to encode the original stimulus configuration by responding either to uncontrolled cues or to one of the rotated cues sets. Thus, the population of cells encoded both the presence of familiar stimuli together with the new organization of those stimuli. During initial double-rotation trials, most place cells had fields that rotated with the controlled cues (Fig. 7), suggesting that these stimuli provided the most important information. After rats had experienced several probe trials, however, fewer cells rotated with the controlled cues, and most cells responded with new firing patterns that apparently encoded the new relationship among the two sets of rotated cues. One might have predicted that repeated double-rotation trials would have caused the rats and their hippocampal cells to ignore one cue set and encode only the other set. The cells continued to encode both cue sets, however, suggesting that the hippocampal system is prepared to use local and distal cues together to compute locations.

Note that the present experiment cannot determine if the change in place field responses was produced by increased familiarity with the environment in general or by specific experience with repeated double-rotation trials. Indeed, the change in response probabilities suggests that repeated experience with changing stimulus relationships (double rotation, cue scrambling, and baseline trials) may have produced the particular distribution of responses that we observed in this experiment.

\section{New Environmental Stimuli Produced New Hippocampal Representations}

In a recent related experiment we used the same basic testing paradigm to explore the extent to which place cells changed their spatial firing patterns when both the local and distal cues, as well as the curtain surrounding the environment, were changed to a new set of cues (Tanila et al., 1997c). After this manipulation, the cells often did not have place fields immediately in the new environment, but rather the fields required at least 5-30 min to develop. Before this time, the fields were sometimes unstable, and in other cases fired rarely or diffusely. As the fields developed, they focused (the spatial selectivity increased), and stabilized. Moreover, the new environment produced a complete remapping of the place fields (Muller and Kubie, 1987; Muller et al., 1987; Quirk et al., 1990; Bostock et al., 1991). All of the cells either lost their fields, that is, stopped firing altogether or became noisy so that no statistically defined place fields remained, or developed new fields, or developed a split place field with one subfield overlapping the place field in the standard environment. Thus, no obvious relationship existed between the place field locations in the familiar and in the new environment despite the presence of the same radial maze and uncontrolled stimuli.

The complete remapping observed after these major cue substitutions contrasts with the effects of double-rotation trials in the present experiment where the same stimuli were spatially reorganized. The reorganization, as described above, produced new representations in $\sim 40 \%$ of the cells, with about the same percent following one of the familiar cue sets. Therefore, while the relationships among local and distal stimuli have important influence on hippocampal place fields, so too does the stimulus content of the environment. The fact that double-rotation trials produced different, but overlapped representations (overlapped in the population vector sense) with the standard baseline trials demonstrates that the stimulus content as well as stimulus relationships are encoded by hippocampal neurons. The fact that the "new environment," which contained the same maze and same uncontrolled stimuli, but not the familiar controlled stimuli, produced a complete remapping of the place fields emphasizes the perhaps obvious fact that hippocampal neurons encode stimulus content prior to stimulus organization. This result also corresponds to those obtained by Gothard et al. (1996a,b), who found that $\sim 30 \%$ of cells that responded to a start box in one environment responded to the same box in an otherwise distinct environment. In both experiments, the hippocampal representation included salient information that was present in otherwise distinct environments.

In another laboratory we have found similar results in an experiment that compared place fields in a familiar, square recording chamber with that in a cylindrical one. We found that within several minutes of experience in a new environment, new place fields developed that remained stable for many days (Hargreaves et al., 1997), and that while $N$-methyl-D-aspartate receptor antagonists did not alter stable firing in the familiar environment, they did prevent stability from developing in the unfamiliar cylinder (Hargreaves et al., 1997; cf. Austin et al., 1990, 1993).

\section{Memory effects}

O'Keefe and Speakman (1987) found that rats trained to remember the location of experimenter-controlled distal stimuli in a spatial working memory task had place fields that persisted when these stimuli were removed (cf. Muller and Kubie, 1987a; 
Quirk et al., 1990). In the present experiment, $\sim 12 \%$ of hippocampal neurons had place fields that did not change during double-rotation trials. Although the simplest explanation of these results may be that the cells responded to uncontrolled external stimuli, the possibility remains that some and perhaps all of these fields were stable because they were generated by internal memory representations. At least one ensemble of four cells was controlled by cues internal to the rat, because these fields rotated with the prior location of the experimenter (Fig. 6). These data suggest that memory can not only substitute for, but can override perceptual influences on place fields. Further experiments are required to determine the extent to which stable place fields are responding to internal as opposed to external stimuli.

\section{What is the role of synaptic plasticity regarding place cells?}

Two forms of plasticity that influence place cells are described in the present results. First, place cell responses switched among different controlling cues when familiar stimuli were organized in new patterns. The appearance of different representations under these conditions is consistent with the activation of related, multistable states in a neural (attractor) network. Second, completely new place fields were formed when rats were first placed in an environment containing unfamiliar stimuli. These new representations required time to become stable and have been shown to require the same plasticity mechanisms as required for long-term potentiation (LTP) (Mayford et al., 1996; Mchugh et al., 1996; Rotenberg et al., 1996; Tsien et al., 1996). An intermediate result was observed after repeated double-rotation trials, which led to an increased incidence of new representations. The two forms of plasticity, selection among multistable states, which we argue are organized hierarchically, and the formation of new representations, may be governed by the presence of familiar and unfamiliar stimuli.

The following is a hypothetical account of how these forms of response flexibility may be computed. When only unfamiliar stimuli are present, the competitive learning rules that control LTP may allow the new stimuli and stimulus relationships [e.g., distances (O'Keefe and Burgess, 1996)] to come to activate a subset of place cells. The competitive learning ensures that the cues that provide the best predictors with regard to environmental contingencies will gain most control over the cells through enhanced synaptic strength. With repeated experience, a subset of stimulus relationships will reliably activate a population of place cells. This subset can also be activated by redundant information which is normally suppressed by competition among the input sets, but can be revealed by probe tests as described above. This active subset of place cells encodes individual locations in an environment, where each location is defined by a set of relationships among stimuli.

The recurrent network in CA3 in turn allows connections among place cells with overlapping place fields to potentiate and encode distance among places (Hetherington and Shapiro, 1993b; Muller et al., 1996). At this stage of familiarity, a cognitive map has been encoded, and individual stimuli are sufficient to activate the map. The individual stimuli can also anchor the map, in the sense that the distance to one or a small subset of the stimuli can activate the map with a specific orientation (e.g., Bostock et al., 1991). This anchoring and activation accounts for the memory cells described above and elsewhere (e.g., O'Keefe and Speakman, 1987). The hierarchy of input strengths will ensure that a subset of familiar stimuli will produce the switching effects reported above. The most common response to double-rotation trials was initially a rotation of place fields with the distal cues, which served to anchor the active representation. As the new organization became more familiar (i.e., encoded as a new environment), the proportion of new representations increased, in part because of the high degree of information provided by the relationship among the cue sets. Cue scrambling and deletion trials, which were more varied and thus repeated less often than double-rotation trials, typically activated one of the multistable states as a subset of cues served to anchor and activate the representation of a familiar environment. When cue scrambling did reproduce a specific conjunction of stimulus relationships that was also present in and activated by double-rotation trials, the same place fields were activated in both trial types (Fig. 2).

\section{REFERENCES}

Andersen P. Synaptic integration in hippocampal CA1 pyramids. Prog Brain Res 1990;83:215-1990; 83:215-222.

Austin KB, Fortin WF, Shapiro ML. Place fields are altered by NMDA antagonist MK-801 during spatial learning. Society for Neuroscience Annual Meeting, St. Louis, MO, October 28, 1990. Soc Neurosci Abstr 1990;16:263.

Austin KB, White LH, Shapiro ML. Short- and long-term effects of experience on hippocampal place fields [Abstract]. Soc Neurosci Abstr 23rd Annual Meeting 1993;19:797.

Berger TW, Alger B, Thompson RF. Neuronal substrate of classical conditioning in the hippocampus. Science 1976;192:483-485.

Bostock E, Muller RU, Kubie JL. Experience-dependent modification of hippocampal place cell firing. Hippocampus 1991;1:193-205.

Bunsey M, Eichenbaum H. Conservation of hippocampal memory function in rats and humans. Nature 1996;379:255-257.

Cohen NJ, Eichenbaum H. Memory, amnesia, and the hippocampal system. Cambridge, MA: MIT Press, 1993.

Donovick PJ. A metachromatic stain for neural tissue. Stain Technol 1974;49:49-51.

Dusek JA, Eichenbaum H. The hippocampus and memory for orderly stimulus relations. Proc Natl Acad Sci USA 1997; in press.

Eichenbaum H. Is the rodent hippocampus just for 'place'? Curr Opin Neurobiol 1996;6:187-195.

Eichenbaum H, Wiener SI. Is place the (only) functional correlate? Psychobiology 1989;17:217-220.

Eichenbaum H, Kuperstein M, Fagan A, Nagode J. Cue-sampling and goal-approach correlates of hippocampal unit activity in rats performing an odor-discrimination task. J Neurosci 1987;7:716-732. 
Eichenbaum H, Fagan A, Matthews P, Cohen NJ. Hippocampal system dysfunction and odor discrimination learning in rats: impairment or facilitation depending on representational demands. Behav Neurosci 1988;102:331-339.

Eichenbaum H, Wiener SI, Shapiro ML, Cohen NJ. The organization of spatial coding in the hippocampus: a study of neural ensemble activity. J Neurosci 1989;9:2764-2775.

Eichenbaum H, Otto T, Cohen NJ. Two functional components of the hippocampal memory system. Behav Brain Sci 1994;17:517.

Fenton AA, Muller RU. How two cues conjointly control hippocampal place cell firing fields. Soc Neurosci Abstr 1996;22:911.

Fox SE, Ranck JB. Electrophysiological characteristics of hippocampal complex-spike cells and theta cells. Exp Brain Res 1981;41:399-410.

Gomori G. Minrotechnical demonstration of iron. Am J Pathol 1936;12: 655-663.

Gothard KM, Skaggs WE, McNaughton BL. Dynamics of mismatch correction in the hippocampal ensemble code for space: interaction between path integration and environmental cues. J Neurosci 1996a; 16:8027-8040.

Gothard KM, Skaggs WE, Moore KM, McNaughton BL. Binding of hippocampal CA1 neural activity to multiple reference frames in a landmark-based navigation task. J Neurosci 1996b;16:823-835.

Hampson RE, Heyser CJ, Deadwyler SA. Hippocampal cell firing correlates of delayed-match-to-sample performance in the rat. Behav Neurosci 1993;107:715-739.

Hampson RE, Byrd DR, Konstantopoulos JK, Bunn T, Deadwyler SA. Hippocampal place fields: relationship between degree of field overlap and cross-correlations within ensembles of hippocampal neurons. Hippocampus 1996;6:281-293.

Hargreaves EL, Li JF, Shapiro ML. NMDA receptor antagonists prevent the formation of stable place fields in the hippocampus of rats exploring an unfamiliar environment. Soc Neurosci Abstr 1997:508.

Hetherington PA, Shapiro ML. Simulating Hebb cell assemblies: the necessity for partitioned dendritic trees and a post-not-pre LTD rule. Network 1993a;4:135-153.

Hetherington PA, Shapiro ML. A simple network model simulates hippocampal place fields: II. Computing goal-directed trajectories and memory fields. Behav Neurosci 1993;107:434-443.

Hetherington PA, Shapiro ML. Hippocampal place fields are altered by the removal of single visual cues in a distance-dependent manner. Behav Neurosci 1997;111:20-34.

Jarrard LE. On the role of the hippocampus in learning and memory in the rat. Behav Neural Biol 1993;60:9-26.

Krebs JR, Sherry DF, Healy SD, Perry VH, Vaccarino AL. Hippocampal specialization of food-storing birds. Proc Natl Acad Sci USA 1989;86: 1388-1392.

Kubie JL, Ranck JB. Sensory-behavioral correlates in individual hippocampus neurons in three situations: space and context. In: Seifert W, ed. The hippocampus. New York: Academic Press, 1983:433-447.

Mayford M, Bach ME, Huang Y-Y, Wang L, Hawkins RD, Kandel ER. Control of memory formation through regulated expression of a CaMKII transgene. Science 1996;274:1678-1683.

Mchugh TJ, Blum KI, Tsien JZ, Tonegawa S, Wilson MA. Impaired hippocampal representation of space in CA1-specific NMDAR1 knockout mice. Cell 1996;87:1339-1349.

McNaughton BL, O'Keefe J, Barnes CA. The stereotrode: a new technique for simultaneous isolation of several single units in the central nervous system from multiple unit records. J Neurosci Methods 1983;8:391-397.

Morris RGM, Garrud P, Rawlins JNP, O'Keefe J. Place navigation impaired in rats with hippocampal lesions. Nature 1982;297:681683.

Muller RU. A quarter century of place cells. Neuron 1996;17:813-822.
Muller RU, Kubie JL. The effects of changes in the environment on the spatial firing of hippocampal complex-spike cells. J Neurosci 1987;7: 1951-1968.

Muller RU, Kubie JL, Ranck JB. Spatial firing patterns of hippocampal complex-spike cells in a fixed environment. J Neurosci 1987;7:19351950.

Muller RU, Stead M, Pach J. The hippocampus as a cognitive graph. J Gen Physiol 1996;107:663-694.

O'Keefe J. Place units in the hippocampus of the freely moving rat. Exp Neurol 1976;51:78-109.

O'Keefe J. A review of the hippocampal place cells. Prog Neurobiol 1979;13:419-439.

O'Keefe J, Burgess N. Geometric determinants of the place fields of hippocampal neurons. Nature 1996;381:425-428.

O'Keefe J, Conway DH. Hippocampal place units in the freely moving rat: why they fire where they fire. Exp Brain Res 1978;31:573-590.

O'Keefe J, Dostrovsky J. The hippocampus as a spatial map. Preliminary evidence from unit activity in the freely-moving rat. Brain Res 1971;34:171-175.

O'Keefe J, Nadel L. The hippocampus as a cognitive map. Oxford: Oxford Univ. Press, 1978.

O'Keefe J, Speakman A. Single unit activity in the rat hippocampus during a spatial memory task. Exp Brain Res 1987;68:1-27.

Olton DS, Becker JT, Handelmann GH. Hippocampus, space and memory. Behav Brain Sci 1979;2:313-365.

Olton DS, Feustle WA. Hippocampal function required for nonspatial working memory. Exp Brain Res 1981;41:380-389.

Olton DS, Branch M, Best PJ. Spatial correlates of hippocampal unit activity. Exp Neurol 1978;58:387-409.

Paxinos G, Watson C. The rat brain in stereotaxic coordinates. Sydney, Australia: Academic Press, 1982.

Quirk GJ, Muller RU, Kubie JL. The firing of hippocampal place cells in the dark depends on the rat's recent experience. J Neurosci 1990;10: 2008-2017.

Ranck JB. Studies on single neurons in dorsal hippocampal formation and septum in unrestrained rats. Part 1. Behavioral correlates and firing properties. Exp Neurol 1973;41:462-531.

Recce ML, O'Keefe J. The tetrode: a new technique for multiunit extracellular recording. Soc Neurosci Abstr 1989;15:1250.

Rotenberg A, Mayford M, Hawkins RD, Kandel ER, Muller RU. Mice expressing activated CAMKII lack low frequency LTP and do not form stable place cells in the CA1 region of the hippocampus. Cell 1996;87:1351-1361.

Sakurai Y. Hippocampal cells have behavioral correlates during the performance of an auditory working memory task in the rat. Behav Neurosci 1990;104:253-263.

Scoville WB, Milner B. Loss of recent memory after bilateral hippocampal lesions. J Neurol Neurosurg Psychiatry 1957;20:11-21.

Shapiro ML, Hetherington PA. A simple network model simulates hippocampal place fields: Parametric analyses and physiological predictions. Behav Neurosci 1993;107:34-50.

Shapiro ML, Simon DK, Olton DS, Gage FH III, Nilsson O, Bjorklund A. Intrahippocampal grafts of fetal basal forebrain tissue alter place fields in the hippocampus of rats with fimbria-fornix lesions. Neuroscience 1989;32:1-18.

Tanila H, Shapiro M, Eichenbaum H. Discordance of spatial representation in ensembles of hippocampal place cells. Hippocampus 1997a; in press.

Tanila H, Shapiro ML, Gallagher M, Eichenbaum H. Brain aging: changes in the nature of information coding by the hippocampus. $\mathrm{J}$ Neurosci 1997b;17:5155-5166.

Tanila H, Sipila P, Shapiro ML, Eichenbaum H. Brain aging: impaired coding of a novel environment. J Neurosci 1997c;17:5167-5179. 
Thompson LT, Best PJ. Place cells and silent cells in the hippocampus of freely-behaving rats. J Neurosci 1989;9:2382-2390.

Tsien JZ, Huerta PT, Tonegawa S. The essential role of hippocampal CA1 NMDA receptor-dependent synaptic plasticity in spatial memory. Cell 1996;87:1327-1338.

Wible CG, Findling RL, Shapiro ML, Lang EJ, Crane S, Olton DS. Mnemonic correlates of unit activity in the hippocampus. Brain Res 1986;399:97-110.
Wiener SI, Paul CA, Eichenbaum H. Spatial and behavioral correlates of hippocampal neuronal activity. J Neurosci 1989;9:2737-2763.

Young BJ, Fox GD, Eichenbaum H. Correlates of hippocampal complexspike cell activity in rats performing a nonspatial radial maze task. J Neurosci 1994a;14:6553-6563.

Young BJ, Fox GD, Eichenbaum H. Correlates of hippocampal complexspike cell activity in rats performing a nonspatial radial maze task. J Neurosci 1994b;14:6553-6563. 